\title{
Hepatitis B Core-Related Antigen as Surrogate Biomarker of Intrahepatic Hepatitis B Virus Covalently-Closed-Circular DNA in Patients with Chronic Hepatitis B: A Meta-Analysis
}

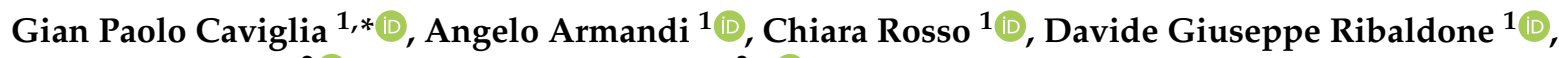 \\ Rinaldo Pellicano $^{2}$ (D) and Sharmila Fagoonee ${ }^{3, * \text { D }}$ \\ 1 Department of Medical Sciences, University of Turin, 10124 Turin, Italy; angelo.armandi@unito.it (A.A.); \\ chiara.rosso@unito.it (C.R.); davidegiuseppe.ribaldone@unito.it (D.G.R.) \\ 2 Unit of Gastroenterology, Città della Salute e della Scienza di Torino-Molinette Hospital, 10126 Turin, Italy; \\ rinaldo_pellican@hotmail.com \\ 3 Institute of Biostructure and Bioimaging (CNR), Molecular Biotechnology Center, 10126 Turin, Italy \\ * Correspondence: gianpaolo.caviglia@unito.it (G.P.C.); sharmila.fagoonee@unito.it (S.F.); \\ Tel.: +39-011-633-3532 (G.P.C.)
}

Citation: Caviglia, G.P.; Armandi, A.; Rosso, C.; Ribaldone, D.G.; Pellicano,

R.; Fagoonee, S. Hepatitis B Core-Related Antigen as Surrogate Biomarker of Intrahepatic Hepatitis B Virus Covalently-Closed-Circular DNA in Patients with Chronic Hepatitis B: A Meta-Analysis. Diagnostics 2021, 11, 187. https://doi.org/10.3390/ diagnostics11020187

Academic Editor: Carmen de Mendoza

Received: 10 December 2020

Accepted: 26 January 2021

Published: 28 January 2021

Publisher's Note: MDPI stays neutral with regard to jurisdictional claims in published maps and institutional affiliations.

Copyright: (c) 2021 by the authors. Licensee MDPI, Basel, Switzerland. This article is an open access article distributed under the terms and conditions of the Creative Commons Attribution (CC BY) license (https:// creativecommons.org/licenses/by/ $4.0 /)$.

\begin{abstract}
Hepatitis B virus (HBV) covalently-closed-circular (ccc)DNA is the key molecule responsible for viral persistence within infected hepatocytes. The evaluation of HBV cccDNA is crucial for the management of patients with chronic HBV infection and for the personalization of treatment. However, the need for liver biopsy is the principal obstacle for the assessment of intrahepatic HBV cccDNA. In the last decade, several studies have investigated the performance of hepatitis B corerelated antigen (HBcrAg) as a surrogate of HBV cccDNA amount in the liver. In this meta-analysis, we collected 14 studies (1271 patients) investigating the correlation between serum HBcrAg and intrahepatic HBV cccDNA. Serum HBcrAg showed a high correlation with intrahepatic HBV cccDNA $(r=0.641,95 \%$ confidence interval (CI) $0.510-0.743, p<0.001)$. In a head-to-head comparison, we observed that the performance of HBcrAg was significantly superior to that of hepatitis B surface antigen ( $r=0.665$ vs. $r=0.475$, respectively, $p<0.001$ ). Subgroup analysis showed that the correlation between $\mathrm{HBcrAg}$ and intrahepatic HBV cccDNA was high, both in hepatitis B e antigen-positive and -negative patients $(r=0.678,95 \%$ CI $0.403-0.840, p<0.001$, and $r=0.578,95 \%$ CI $0.344-0.744, p<0.001$, respectively). In conclusion, the measurement of serum HBcrAg qualifies as a reliable non-invasive surrogate for the assessment of an intrahepatic HBV cccDNA reservoir.
\end{abstract}

Keywords: chronic HBV infection; HBcrAg; HBeAg; HBsAg; HBV cccDNA

\section{Introduction}

Hepatitis B virus (HBV) infection is a major health problem worldwide [1]; the estimated prevalence of $\mathrm{HBV}$ infected patients in the world is approximately 257 million $(3.7 \%)$ [2]. Chronic hepatitis B (CHB) is the result of an acute, unresolved infection that overtime may lead to cirrhosis and its complications such as liver failure and hepatocellular carcinoma (HCC) [3].

HBV covalently-closed-circular-(ccc)DNA is the key molecule responsible for the persistence of the virus within infected hepatocytes [4], even decades after resolution of HBV infection [5]. The HBV minichromosome acts as a template for all viral transcripts including the sub-genomic RNAs, pre-core RNA, and pre-genomic RNA [6].

Measuring the quantity and replication activity of HBV cccDNA is of paramount importance to improve the management of patients with $\mathrm{CHB}$ infection and to tailor individualized treatment strategies [7]. Unfortunately, the direct assessment of intrahepatic HBV cccDNA reservoir is limited in clinical practice by the need for liver biopsy $[8,9]$. Lately, exosomes derived from the serum of CHB patients were found to contain both HBV 
nucleic acids and HBV proteins, and could act as carriers of the virus, its nucleic acids, and proteins for further infection of uninfected hepatocytes [10]. Exosomes are 30-150 nm diameter bilipid-layered vesicles secreted by almost all cell types into body fluids including serum, plasma, saliva, and urine. Exosomes contain proteins, lipids, several RNA species as well as DNA, which can reflect the status of the host cells. Exosomes can participate in HBV replication and modulation of the host's immune response, and their miRNA content can serve as biomarkers for HBV diagnosis [11]. Interestingly, the finding of HBV cccDNA inside exosomes by polymerase chain reaction (PCR) suggests that patient serum exosomes are promising sources of nucleic acids for HBV cccDNA analysis [10]. Further studies are needed in this field.

Among the available serum biomarkers, HBV DNA strongly correlates with intrahepatic HBV cccDNA levels; however, during antiviral treatment with nucleos(t)ide analogues (NAs), HBV DNA became rapidly undetectable and thus no longer informative [12]. Hepatitis B surface antigen (HBsAg), the serological hallmark of HBV infection, has been proposed to reflect the liver content of HBV cccDNA $[13,14]$. Recently, it has been shown that different mechanisms exist for HBsAg synthesis and secretion including transcription from HBV S-gene sequences integrated into the host genome [15]. Therefore, the reliability of HBsAg as a surrogate of intrahepatic HBV cccDNA may be questionable.

Hepatitis B core-related antigen $(\mathrm{HBcrAg})$ is a composite biomarker that simultaneously measures hepatitis $\mathrm{B}$ core antigen $(\mathrm{HBcAg})$, hepatitis $\mathrm{B}$ e antigen $(\mathrm{HBe} \mathrm{Ag})$, and a $22 \mathrm{KDa}$ core-related protein (p22cr) that constitutes the capsid of HBV empty particles [16]. This biomarker proved to be useful for the discrimination between the different phases of chronic HBV infection (particularly for the correct identification of patients with HBeAg-negative chronic infection) [17-19], for the management of patients under antiviral treatment [20], for the prediction of HBV reactivation following pharmacological immunosuppression [21], and for the stratification of the risk of HCC development as well as its recurrence [22]. Finally, HBcrAg exhibited a good correlation with intrahepatic HBV cccDNA quantity and productivity [23].

Here, we performed a meta-analysis on the value of $\mathrm{HBcrAg}$ as a surrogate of intrahepatic HBV cccDNA. Furthermore, we evaluated the performance of HBcrAg compared to HBsAg as indirect markers of HBV cccDNA, and we conducted a subgroup analysis according to HBeAg-positivity.

\section{Materials and Methods}

\subsection{Search Strategy}

This meta-analysis was performed according to the PRIMA (Preferred Reporting Items for Systematic Reviews and Meta-analyses) guidelines [24]. Original research articles published in English on the correlation between serum HBcrAg and intrahepatic HBV cccDNA quantity were identified through the PubMed (https:/ / pubmed.ncbi.nlm.nih.gov) and Scopus (https:/ / www.scopus.com) databases. The search strategy was based on the following terms: "(HBcrAg[All Fields] OR hepatitis B core-related antigen[All Fields]) AND (cccDNA[All Fields] OR covalently-closed-circular DNA[All Fields])". The search on both databases was performed on 20 November 2020.

\subsection{Study Selection}

Two authors (G.P.C. and R.P.) independently reviewed the titles and the abstract of the studies retrieved from the electronic search and selected those potentially relevant for the purpose of the meta-analysis. The full-text versions of selected studies were assessed by three authors (G.P.C., R.P., and S.F.) to determine whether the inclusion criteria were satisfied.

The inclusion criteria were: (1) original research articles published in English; and (2) studies reporting the correlation coefficients between HBcrAg and intrahepatic HBV cccDNA. No restrictions were imposed concerning virologic and clinical features of patients included in the studies, method for HBV cccDNA measurement, and ongoing antiviral therapy. Exclusion criteria were: (1) studies that did not estimate the correlation between 
HBcrAg and intrahepatic HBV cccDNA; (2) in vitro studies; and (3) reviews, case reports, and meta-analysis.

\subsection{Index and Reference Test}

The measurement of serum HBcrAg was defined as the index test. Currently, serum HBcrAg can be evaluated only by a chemiluminescent enzyme immunoassay (CLEIA) on the Lumipulse ${ }^{\circledR} G$ system (Fujirebio, Tokyo, Japan). The assay measures HBeAg, $\mathrm{HBcAg}$, and p22cr and the concentration is calculated by comparison with a standard curve generated using recombinant pro-HBeAg. The immunoreactivity of pro-HBeAg at $10 \mathrm{fg} / \mathrm{mL}$ is defined as $1 \mathrm{U} / \mathrm{mL}$. HBcrAg values are usually expressed as $\log \mathrm{U} / \mathrm{mL}$, with a measurement range between 3.0-7.0 $\mathrm{Log} \mathrm{U} / \mathrm{mL}$. Some authors used to report HBcrAg concentration in serum as $\mathrm{kU} / \mathrm{mL}$.

The direct quantitation of intrahepatic HBV cccDNA was defined as the reference test (i.e., gold standard). However, it should be noted that no standard method has yet been identified for the measurement of HBV cccDNA; there is still no consensus on the protocol for HBV cccDNA isolation from liver tissue including the enzymatic digestion of relaxed HBV DNA, the specific primers for HBV cccDNA amplification, and the normalization of quantity PCR data. Intrahepatic HBV cccDNA is usually reported as copies/cell, copies/ $\mu \mathrm{g}$ or copies/cell equivalent (cEq).

\subsection{Data Extraction and Quality Assessment}

From selected papers, the same two authors (G.P.C. and R.P.) extracted data regarding authors, country, year of publication, type of study, number of patients, virologic and clinical characteristics of patients, methods used for HBV cccDNA quantification, mean or median HBV cccDNA, HBcrAg, and HBsAg values, correlation coefficients $(r)$, and $p$ values.

The quality of included studies was assessed according to the QUADAS-2 (Quality Assessment of Diagnostic Accuracy Studies version 2) criteria [25].

\subsection{Statistical Analysis}

The meta-analysis was performed using MedCalc ${ }^{\circledR}$ software version 18.9.1 (MedCalc bvba, Ostend, Belgium). The test for inter-rater agreement (Cohen Kappa statistics; K) was used to evaluate the agreement between investigators. The pooled correlation coefficient with 95\% confidence interval (CI) was calculated from the number of cases, the $r$ with $95 \%$ CI from all the included studies.

Forest plots showing the overall effect and funnel plots for publication bias assessment were constructed. According to the presence of heterogeneity, a fixed or random effects model was employed. Cochran's $Q$ and $I^{2}$ statistics were used to detect heterogeneity; a $p$ value $<0.05$ was considered as indicative of heterogeneity.

Begg and Mazumdar's rank correlation test (Kendall's tau; $T$ ) was performed to measure the funnel plots' asymmetry [26]. The standard normal deviate, defined as the natural logarithm of estimate divided by its standard error (SE), was correlated to the estimate's precision, defined as the inverse of the SE. SE was calculated with the following formula: $\mathrm{SE}=(\ln \mathrm{UB}-\ln \mathrm{LB}) / 2 \times 1.96$, where $\mathrm{UB}$ and $\mathrm{LB}$ are the upper and lower bound of the $95 \%$ CI of $r$, respectively.

Comparison between correlation coefficients was performed by z-statistics.

\section{Results}

\subsection{Description of the Study Population}

Of the 54 articles identified through our systematic search, 14 met the eligibility criteria (Figure 1) [23-39]. There was no disagreement among authors regarding the eligibility of original articles finally included in the meta-analysis $(K$ statistics $=1)$. 


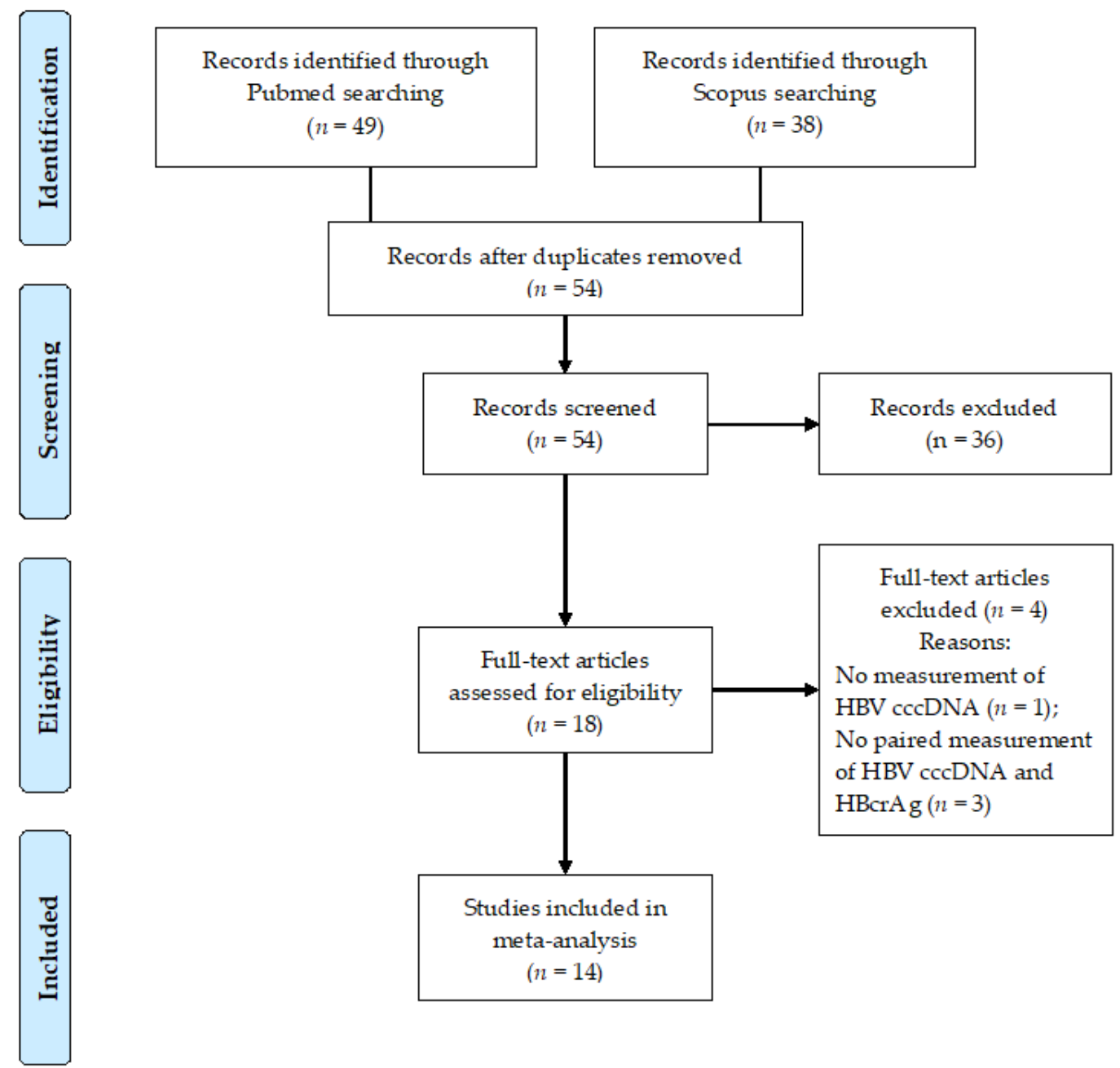

Figure 1. Flow diagram of the study. Abbreviations: covalently-closed-circular DNA (cccDNA), hepatitis B core-related antigen (HBcrAg), hepatitis B virus (HBV), number $(n)$.

Overall, 1271 patients chronically infected with HBV were included in the present meta-analysis (Table 1). Most studies were performed in East Asia $(11 / 14 ; 78.6 \%)$ and the majority in China $(n=6)[27,31,32,34,36,37]$. Only three studies came from European countries (two from France and one from Italy) [23,38,39]. Consistently, the most represented genotypes were the HBV genotype $\mathrm{C}(n=376)$, followed by genotype $\mathrm{B}(n=230)$; the HBV genotype was not available for 525 patients (41.3\%). Data concerning HBeAgpositivity was available for 985 patients $(77.5 \%)$; 515 patients were HBeAg-positive (52.3\%), while 470 were HBeAg-negative (47.7\%). The liver disease was complicated by HCC in 266 patients (20.9\%) [26,31,32]; 31 patients were co-infected with human immunodeficiency virus (HIV) [36]. Only the minority of patients were under nucleos(t)ide analogues (NAs) treatment at the time of HBcrAg and HBV cccDNA evaluation [29,39]. Two studies assessed serum HBV biomarkers and intrahepatic HBV cccDNA before NAs initiation and during treatment $[31,36]$. 
Table 1. Characteristics of the studies included in the meta-analysis.

\begin{tabular}{|c|c|c|c|c|c|c|c|c|c|c|c|}
\hline Study & Country & Year & $\begin{array}{l}\text { Patients } \\
\quad(n)\end{array}$ & $\begin{array}{c}\text { HBeAg } \\
(+/-)\end{array}$ & $\begin{array}{c}\text { HBV } \\
\text { Genotype }\end{array}$ & Therapy & HBcrAg & HBsAg & HBV cccDNA & $\begin{array}{c}r^{*} \\
p \text {-Value }\end{array}$ & $\begin{array}{c}r^{* *} \\
p \text {-Value }\end{array}$ \\
\hline $\begin{array}{l}\text { Wong DKA } \\
\text { [27] }\end{array}$ & China & 2007 & 54 & $17 / 37$ & n.a. & No & $\begin{array}{c}1180(<1.0-9.0 \times \\
\left.10^{5}\right) \\
\mathrm{kU} / \mathrm{mL}\end{array}$ & n.a. & $\begin{array}{c}1.3(<0.002-23.3) \\
\text { copies / cell }\end{array}$ & $\begin{array}{l}r=0.664 \\
p<0.001\end{array}$ & n.a. \\
\hline $\begin{array}{c}\text { Suzuki F } \\
\text { [28] }\end{array}$ & Japan & 2009 & 44 & $16 / 28$ & n.a. & No & $\begin{array}{c}5.05 \pm 1.62 \\
\log \mathrm{U} / \mathrm{mL} \\
\mathrm{e}+: 6.53 \pm 1.14 \\
\log \mathrm{U} / \mathrm{mL} \\
\mathrm{e}-: 4.20 \pm 1.18 \\
\log \mathrm{U} / \mathrm{mL}\end{array}$ & $\begin{array}{l}\text { n.a. } \\
\text { n.a. } \\
\text { n.a. }\end{array}$ & $\begin{array}{c}4.46 \pm 0.87 \\
\text { Log copies } / \mathrm{mg} \\
\mathrm{e}+: 4.88 \pm 1.06 \\
\text { Log copies } / \mathrm{mg} \\
\mathrm{e}-: 4.23 \pm 0.64 \\
\text { Log copies } / \mathrm{mg}\end{array}$ & $\begin{array}{c}\text { n.a. } \\
r=0.687 \\
p=0.003 \\
r=0.542 \\
p=0.003\end{array}$ & $\begin{array}{l}\text { n.a. } \\
\text { n.a. } \\
\text { n.a. }\end{array}$ \\
\hline $\begin{array}{c}\text { Hosaka T } \\
\text { [29] }\end{array}$ & Japan & 2010 & $55^{\mathrm{A}}$ & $23 / 32$ & $\begin{array}{c}C=51 \\
\text { Other }=9\end{array}$ & $\begin{array}{c}30 \text { LAM } \\
17 \text { LAM + ADV } \\
8 \text { ETV }\end{array}$ & $\begin{array}{c}5.0(<3.0->6.8) \\
\log \mathrm{U} / \mathrm{mL}\end{array}$ & n.a. & $\begin{array}{c}4.2(3.0-5.0) \\
\text { Log copies/ } / \mu \mathrm{g}\end{array}$ & $\begin{array}{c}r=0.479 \\
p=0.028^{\mathrm{B}}\end{array}$ & n.a. \\
\hline $\begin{array}{c}\text { Chuaypen } \mathrm{N} \\
{[30]}\end{array}$ & Thailand & 2016 & 46 & $46 / 0$ & $\begin{aligned} B & =5 \\
C & =41\end{aligned}$ & No & $\begin{array}{l}8.1(7.7-8.4) \\
\log U / m L\end{array}$ & $\begin{array}{l}3.9(3.7-4.1) \\
\log I U / m L\end{array}$ & $\begin{array}{l}1.6(1.2-1.9) \\
\text { copies/cEq }\end{array}$ & $\begin{array}{l}r=0.564 \\
p=0.001\end{array}$ & $\begin{array}{l}r=0.424 \\
p=0.020\end{array}$ \\
\hline $\begin{array}{c}\text { Wong DKA } \\
{[31]}\end{array}$ & China & 2017 & 138 & $77 / 61$ & $\begin{array}{c}B=40 \\
C=82 \\
\text { n.a. }=16\end{array}$ & $\begin{array}{c}\text { Baseline } \\
1 \text { year NAs } \\
6-12 \text { years NAs }\end{array}$ & $\begin{array}{c}586\left(1-1.1 \times 10^{7}\right) \\
\mathrm{kU} / \mathrm{mL}^{\mathrm{C}}\end{array}$ & $\begin{array}{l}3.3(-1.3-5.9) \\
\mathrm{Log} \mathrm{IU} / \mathrm{mL}^{\mathrm{C}}\end{array}$ & $\begin{array}{l}1.1(0.005-258) \\
\text { copies/cell C }\end{array}$ & $\begin{array}{c}r=0.70 \\
p<0.001 \mathrm{C}\end{array}$ & $\begin{array}{c}r=0.40 \\
p<0.001 \mathrm{C}\end{array}$ \\
\hline $\begin{array}{c}\text { Chuaypen } \mathrm{N} \\
{[33]}\end{array}$ & Thailand & 2018 & $121^{\mathrm{D}}$ & $0 / 121$ & $\begin{array}{l}B=25 \\
C=96\end{array}$ & No & $\begin{array}{c}\text { R: } 4.1 \pm 1.3 \\
\log \mathrm{U} / \mathrm{mL} \\
\text { NR: } 4.4 \pm 1.1 \\
\log \mathrm{U} / \mathrm{mL}\end{array}$ & $\begin{array}{c}\text { R: } 3.2 \pm 0.4 \\
\log \mathrm{IU} / \mathrm{mL} \\
\text { NR: } 3.6 \pm 0.5 \\
\log \mathrm{IU} / \mathrm{mL}\end{array}$ & $\begin{array}{c}\text { R: } 0.4 \pm 0.9 \\
\text { Log copies/cEq } \\
\text { NR: } 0.4 \pm 1.2 \\
\text { Log copies/cEq }\end{array}$ & $\begin{array}{l}r=0.393 \\
p=0.009\end{array}$ & $\begin{array}{l}r=0.040 \\
p=0.737\end{array}$ \\
\hline $\begin{array}{c}\text { Chen S } \\
\text { [34] }\end{array}$ & China & 2018 & $160^{\mathrm{E}}$ & n.a. & n.a. & n.a. & $\begin{array}{c}5.10(1.96-8.50) \\
\log \mathrm{U} / \mathrm{mL}\end{array}$ & $\begin{array}{c}250(0.14-250) \\
\mathrm{IU} / \mathrm{mL}\end{array}$ & n.a. & $\begin{array}{c}r=0.436 \\
p<0.001^{\mathrm{F}}\end{array}$ & n.a. \\
\hline $\begin{array}{c}\text { Hasegawa K } \\
\text { [35] }\end{array}$ & Japan & 2018 & $126^{\mathrm{G}}$ & n.a. & n.a. & $\begin{array}{c}\text { Untreated, } \\
n=57(\mathrm{~A}) \\
\text { previous NAs, } \\
n=69(\mathrm{~B})\end{array}$ & $\begin{array}{c}\text { A: } 3.0(2.0-7.0) \\
\log \mathrm{U} / \mathrm{mL} \\
\text { B: } 4.1(2.0-7.0) \\
\log \mathrm{U} / \mathrm{mL}\end{array}$ & $\begin{array}{c}\text { A: } 1692.7(0.05-91960.7) \\
\text { IU /mL } \\
\text { B: } 1050.0(0.05-71583.0) \\
\text { IU } / \mathrm{mL}\end{array}$ & 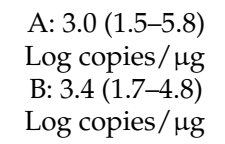 & $\begin{array}{c}\text { A: } r=0.67 \\
p<0.001 \\
\text { B: } r=0.38 \\
p=0.007\end{array}$ & $\begin{array}{c}\text { A: } r=0.59 \\
p<0.001 \\
\text { B: } r=0.32 \\
p=0.007\end{array}$ \\
\hline $\begin{array}{c}\text { Wang L } \\
\text { [36] }\end{array}$ & China & 2019 & 82 & $\begin{array}{l}82 / 0(\mathrm{~A}) \\
44 / 12(\mathrm{~B})\end{array}$ & n.a. & $\begin{array}{c}\text { Baseline (A) } \\
2 \text { years NAs (B) }\end{array}$ & $\begin{array}{c}\text { A: } 7.97 \pm 0.96 \\
\log U / \mathrm{mL} \\
\text { B: } 5.74 \pm 1.10 \\
\log \mathrm{U} / \mathrm{mL}\end{array}$ & $\begin{array}{c}\text { A: } 4.05 \pm 0.64 \\
\log \mathrm{IU} / \mathrm{mL} \\
\mathrm{B}: 3.32 \pm 0.90 \\
\log \mathrm{IU} / \mathrm{mL}\end{array}$ & $\begin{array}{c}\text { A: } 0.67 \pm 0.74 \\
\text { Log copies/cell } \\
\text { B: }-0.94 \pm 0.60 \\
\text { Log copies/cell }\end{array}$ & $\begin{array}{c}\text { A: } r=0.323^{\mathrm{H}} \\
p<0.001 \\
\text { B: } r=0.108 \\
p=0.403\end{array}$ & $\begin{array}{c}\text { A: } r=0.152 \\
p=0.172 \\
\text { B: } r=0.39 \\
p=0.002\end{array}$ \\
\hline
\end{tabular}


Table 1. Cont.

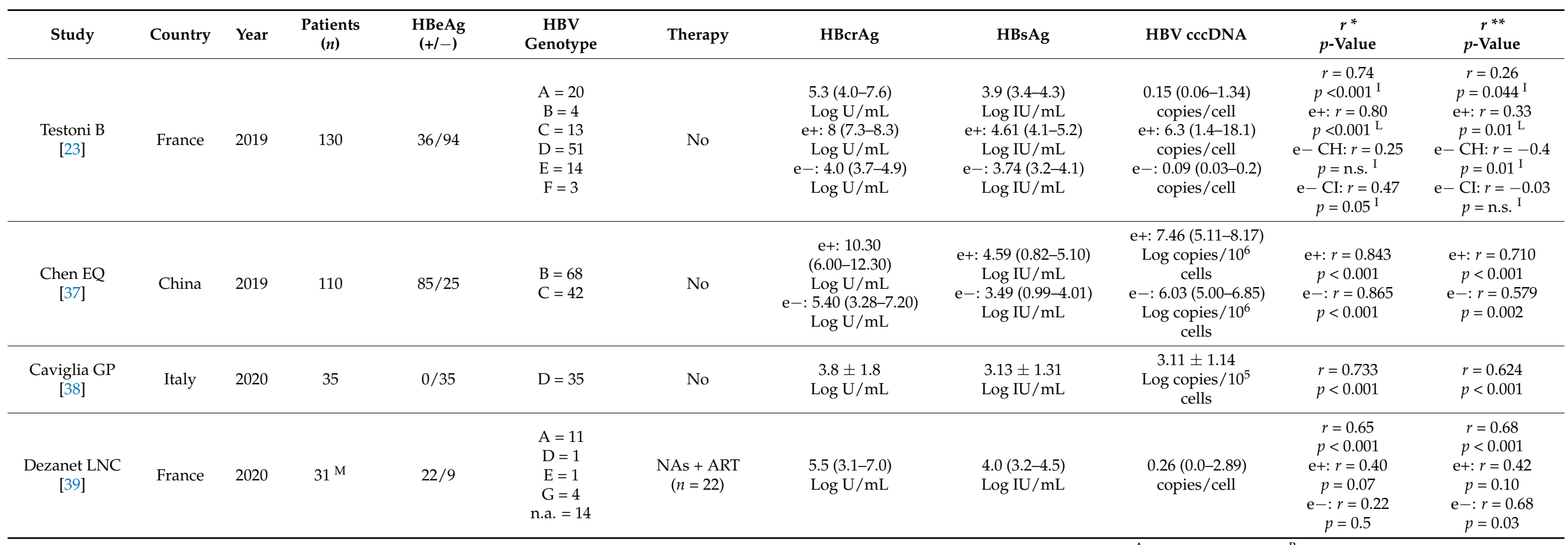

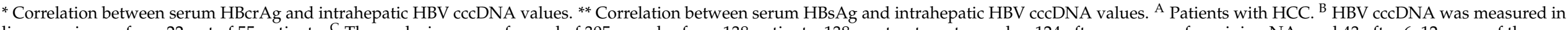

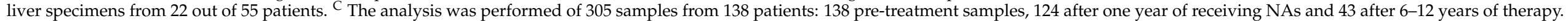

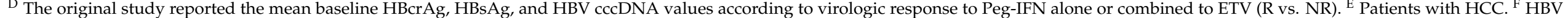

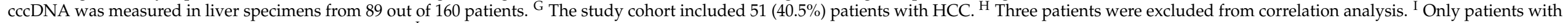

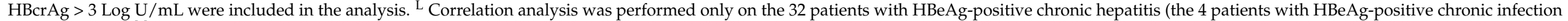

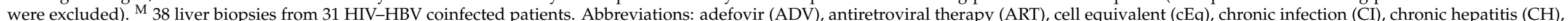

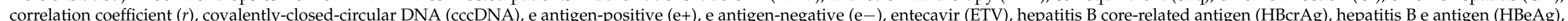

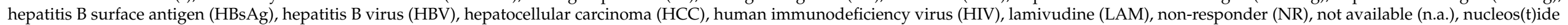
analogues (NAs), number (n), responder (R). 
In most studies, HBV cccDNA was isolated from frozen liver biopsy/specimens stored at $-80^{\circ} \mathrm{C}$; only Chen and colleagues isolated HBV cccDNA from formalin-fixed paraffinembedded liver tissue $[32,37]$. In order to achieve a HBV cccDNA specific quantitation, authors used specific primers for HBV cccDNA amplification (i.e., primers flanking the gap region of HBV genome), with [23,31,32,34,36-39] or without [28-30,33,35] previous plasmid-safe ATP dependent DNase treatment to digest single-strand and relaxed doublestrand DNA isolated from liver tissue samples. In one study, intrahepatic HBV DNA was purified by the modified Hirt procedure and amplified by the Invader HBV assay [27]. HBV cccDNA was quantified by real-time PCR in the majority of the studies; in one study, HBV cccDNA was quantified by droplet-digital PCR [38].

The methodological quality assessment of the included research articles is shown in Figure 2. The overall quality of the studies was high. To note, the higher rate of a potential source of bias pertained to reference standard domain; five out of 14 studies (35.7\%) reported no enzymatic digestion of total intrahepatic DNA prior to HBV cccDNA amplification. Indeed, this methodological aspect is crucial in order to improve PCR specificity [37].

\begin{tabular}{|c|c|c|c|c|c|c|c|}
\hline \multirow{2}{*}{ Study } & \multicolumn{4}{|c|}{ Risk of bias } & \multicolumn{3}{|c|}{ Applicability concerns } \\
\hline & $\begin{array}{c}\text { Patient } \\
\text { selection }\end{array}$ & $\begin{array}{c}\text { Index } \\
\text { test }\end{array}$ & $\begin{array}{l}\text { Reference } \\
\text { standard }\end{array}$ & $\begin{array}{c}\text { Flow and } \\
\text { timing }\end{array}$ & $\begin{array}{c}\text { Patient } \\
\text { selection }\end{array}$ & $\begin{array}{c}\text { Index } \\
\text { test }\end{array}$ & $\begin{array}{l}\text { Reference } \\
\text { standard }\end{array}$ \\
\hline $\begin{array}{l}\text { Wong DKH } \\
{[27]}\end{array}$ & (:) & ;) & (:) & (-) & (-) & (:) & (-) \\
\hline $\begin{array}{l}\text { Suzuki F } \\
{[28]}\end{array}$ & ;) & (-) & $E$ & ;) & (:) & ;:) & ? \\
\hline $\begin{array}{l}\text { Hosaka T } \\
\text { [29] }\end{array}$ & ? & (-) & $E$ & (:) & (-) & (-) & ? \\
\hline $\begin{array}{l}\text { Chuaypen N } \\
\text { [30] }\end{array}$ & ;) & ;) & \% & ;) & ;:) & (-) & ? \\
\hline $\begin{array}{l}\text { Wong DKH } \\
\text { [31] }\end{array}$ & (-) & ;:) & ;:) & (-) & ? & ;: & ;:) \\
\hline $\begin{array}{l}\text { Chen EQ } \\
\text { [32] }\end{array}$ & (:) & ;) & (-) & (-) & (-) & (-) & (-) \\
\hline $\begin{array}{l}\text { Chuaypen N } \\
\text { [33] }\end{array}$ & ? & (-) & $\varepsilon$ & (-) & ? & ;) & ? \\
\hline $\begin{array}{l}\text { Chen S } \\
{[34]}\end{array}$ & ? & (-) & ? & ;:) & (:) & (-) & ? \\
\hline $\begin{array}{l}\text { Hasegawa K } \\
\text { [35] }\end{array}$ & (-) & ;) & F & (-) & (:) & ;) & ? \\
\hline $\begin{array}{l}\text { Wang L } \\
{[36]}\end{array}$ & ㅇ. & (-) & ;) & (-) & : & ;) & (-) \\
\hline $\begin{array}{l}\text { Testoni B } \\
{[23]}\end{array}$ & (:) & ;) & (-) & (:) & (-) & (:) & ;:) \\
\hline $\begin{array}{l}\text { Chen EQ } \\
{[37]}\end{array}$ & (:) & (:) & (:) & ;: & (:) & (:) & ;) \\
\hline $\begin{array}{l}\text { Caviglia GP } \\
{[38]}\end{array}$ & ;) & ;) & (-) & ;) & (-) & (:) & ;) \\
\hline $\begin{array}{l}\text { Dezanet LNC } \\
\text { [39] }\end{array}$ & ;:) & ;) & ;:) & ;) & ? & ;) & (:) \\
\hline
\end{tabular}
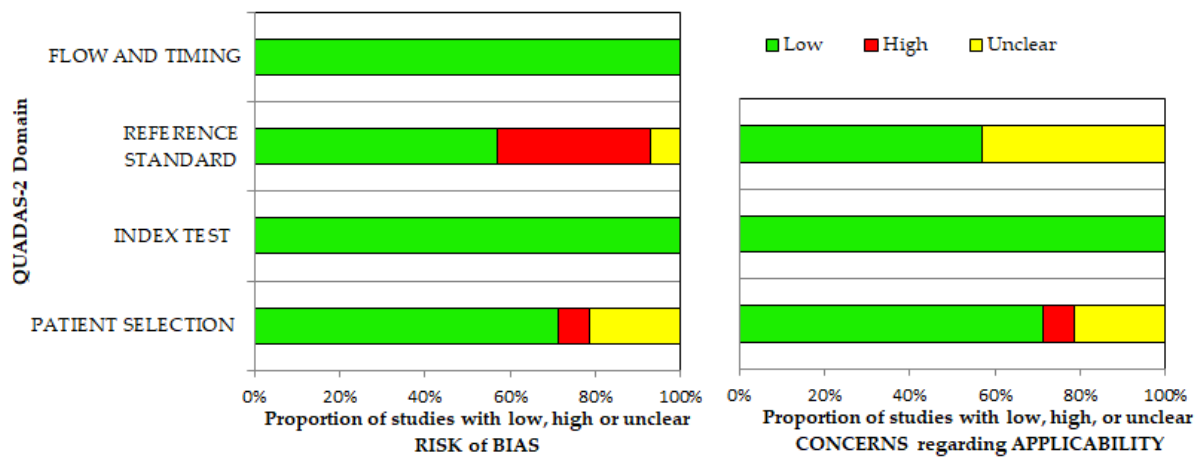

Figure 2. Overall methodology quality assessment of included studies using QUADAS-2 criteria. Abbreviations: Quality Assessment of Diagnostic Accuracy Studies version 2 (QUADAS-2). 


\subsection{Correlation between Serum HBcrAg and Intrahepatic HBV cccDNA}

The correlation coefficients retrieved from correlation analyses between serum $\mathrm{HBcrAg}$ values and intrahepatic HBV ccDNA were analyzed by using forest plot (Figure 3A). Since the studies showed heterogeneity (Cochran's $Q, p<0.001 ; I^{2}=91.6 \%$ ), a random effects model was applied. The result showed a strong positive correlation between HBcrAg and HBV cccDNA ( $r=0.641,95 \%$ CI $0.510-0.743, p<0.001)$. A funnel plot was depicted to visually inspect for possible publication bias (Figure $3 \mathrm{~B}$ ). Kendall rank correlation analysis showed significant publication bias $(T=-0.503, p=0.003)$.

A

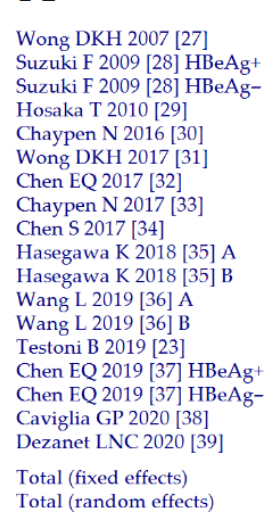

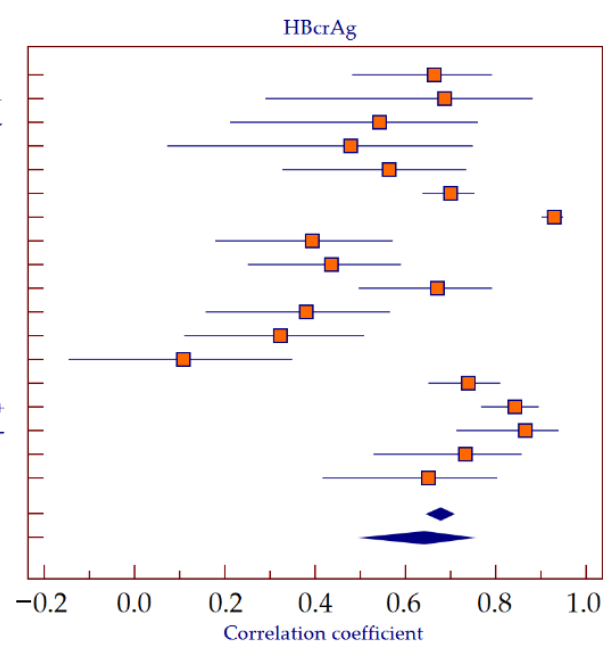

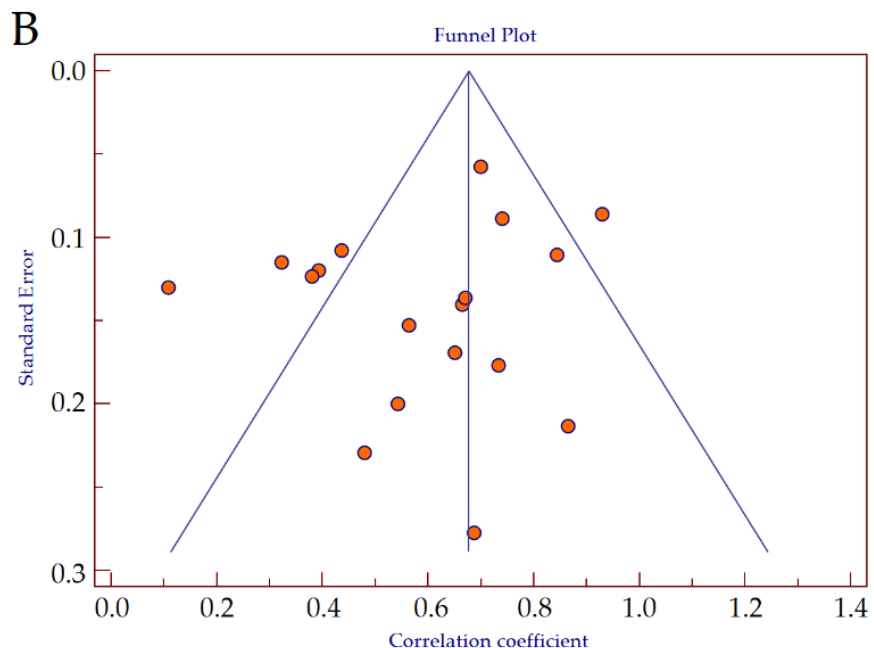

Figure 3. Forest plot (A) and funnel plot (B) of the correlation between serum HBcrAg and intrahepatic HBV cccDNA. Abbreviations: hepatitis B core-related antigen (HBcrAg), hepatitis B virus (HBV), covalently-closed-circular DNA (cccDNA).

\subsection{Comparison between HBcrAg and HBsAg Performance}

We performed a head-to-head comparison of the performance of HBcrAg and HBsAg as surrogate biomarkers of intrahepatic HBV cccDNA including only the studies that provided both data $[23,27-30,32-36]$. The correlation coefficients retrieved from correlation analyses between serum $\mathrm{HBcrAg}$ values and intrahepatic $\mathrm{HBV}$ cccDNA were analyzed by using forest plot (Figure 4A). Since the studies showed heterogeneity (Cochran's $Q$, $p<0.001 ; I^{2}=93.6 \%$ ), a random effects model was applied. The result showed a strong positive correlation between HBcrAg and HBV cccDNA ( $r=0.665,95 \%$ CI 0.507-0.779, $p<0.001$ ). A funnel plot was depicted to visually inspect for possible publication bias (Figure 4B). Kendall rank correlation analysis showed significant publication bias $(T=-0.436$, $p=0.033)$.

The correlation coefficients retrieved from correlation analyses between serum HBsAg values and intrahepatic HBV cccDNA were analyzed by using forest plot (Figure 4C). Since the studies showed heterogeneity (Cochran's $Q, p<0.001 ; I^{2}=85.6 \%$ ), a random effects model was applied. The result showed a moderate positive correlation between HBsAg and HBV cccDNA $(r=0.475,95 \%$ CI $0.339-0.592, p<0.001)$. The corresponding funnel plot is depicted in Figure $4 \mathrm{D}$. Kendall rank correlation analysis showed significant publication bias $(T=0.821, p<0.001)$.

By direct comparison of the summary correlation coefficients, we observed that the performance of HBcrAg was significantly superior to HBsAg (z-statistics, $p<0.001$ ). 
A

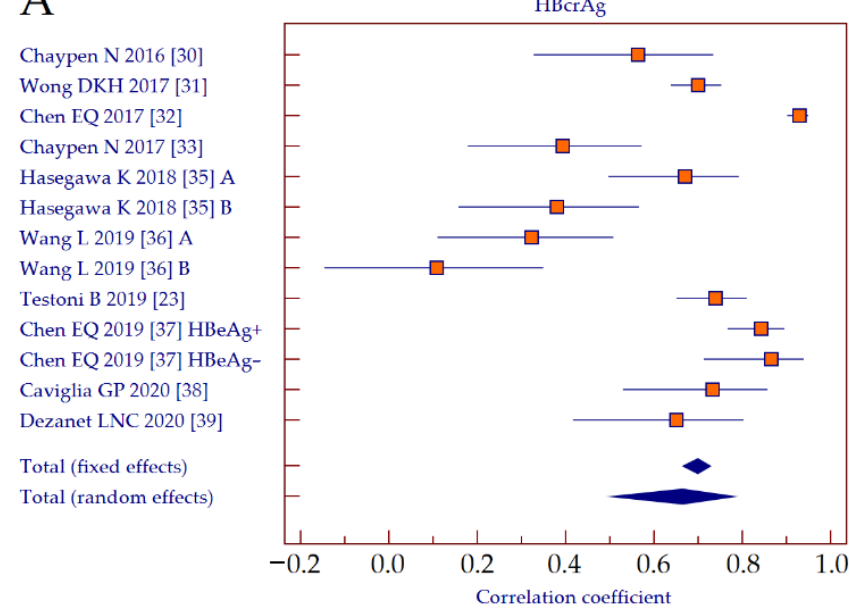

\section{C}

Chaypen N 2016 [30] Wong DKH 2017 [31] Chen EQ 2017 [32] Chaypen N 2017 [33] Hasegawa K 2018 [35] A Hasegawa K 2018 [35] B Wang L 2019 [36] A Wang L 2019 [36] B Testoni B 2019 [23] Chen EQ 2019 [37] HBeAg+ Chen EQ 2019 [37] HBeAgCaviglia GP 2020 [38] Dezanet LNC 2020 [39] Total (fixed effects) Total (random effects)

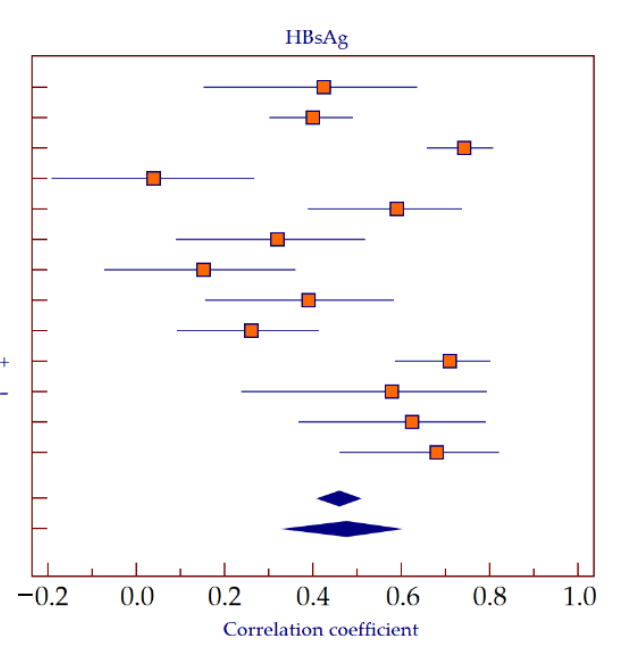

B

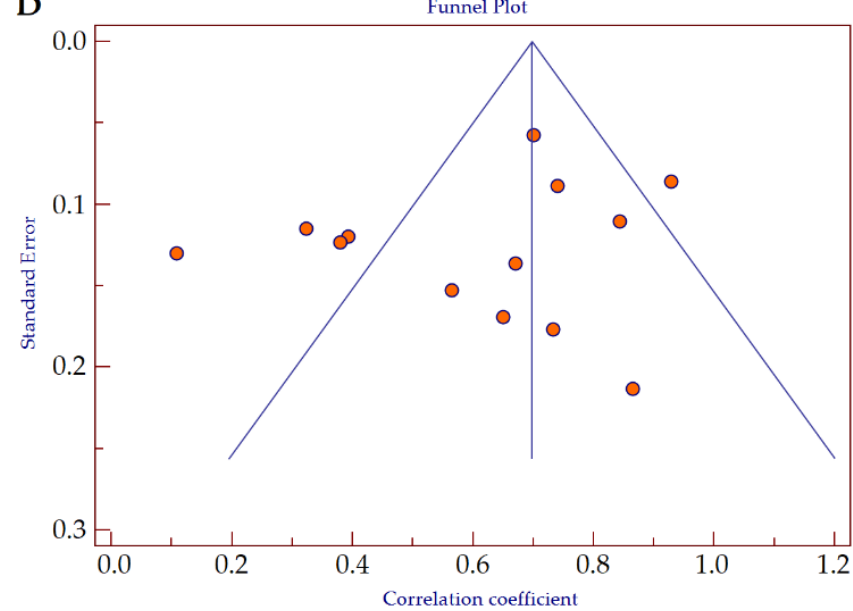

$\mathrm{D}$

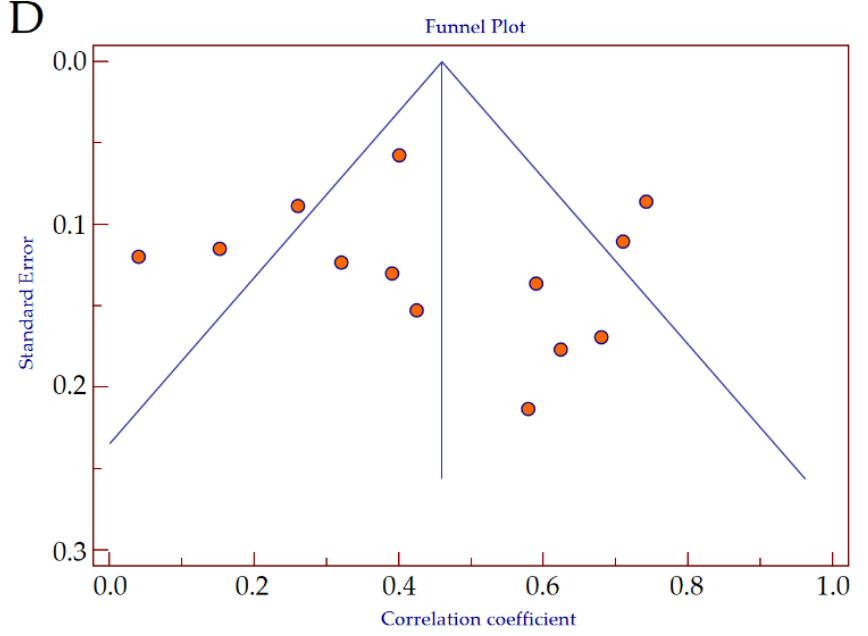

Figure 4. Forest plot (A) and funnel plot (B) of the correlation between serum HBcrAg and intrahepatic HBV cccDNA, and forest plot (C) and funnel plot (D) of the correlation between serum HBsAg and intrahepatic HBV cccDNA. Abbreviations: hepatitis B core-related antigen (HBcrAg), hepatitis B surface antigen (HBsAg), hepatitis B virus (HBV), covalently-closedcircular DNA (cccDNA).

\subsection{Performance of HBcrAg According to HBeAg-Positivity}

We performed a sub-analysis to investigate the performance of $\mathrm{HBcrAg}$ as a surrogate biomarker of intrahepatic HBV cccDNA, according to HBeAg-positivity. The correlation coefficients retrieved from studies investigating the between serum HBcrAg values and intrahepatic HBV cccDNA in HBeAg-positive patients were analyzed by using a forest plot (Figure 5A) [23,25,27,33,34]. Since the studies showed heterogeneity (Cochran's $Q, p<0.001$; $I^{2}=88.9 \%$ ), a random effects model was applied. The result showed a strong positive correlation between HBcrAg and HBV cccDNA ( $r=0.678,95 \%$ CI 0.403-0.840, $p<0.001)$. A funnel plot was depicted to visually inspect for possible publication bias (Figure 5B). Kendall rank correlation analysis indicated no publication bias $(T=-0.200, p=0.462)$. 
A

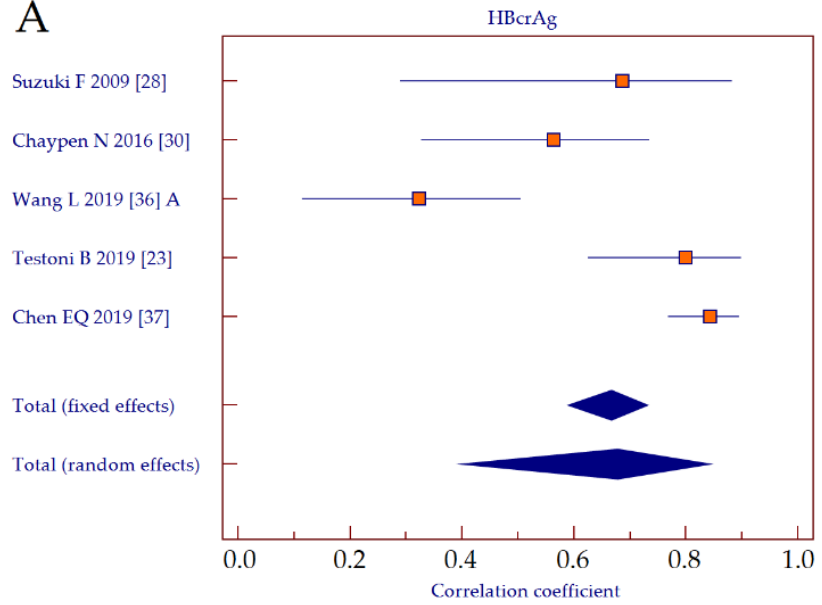

C

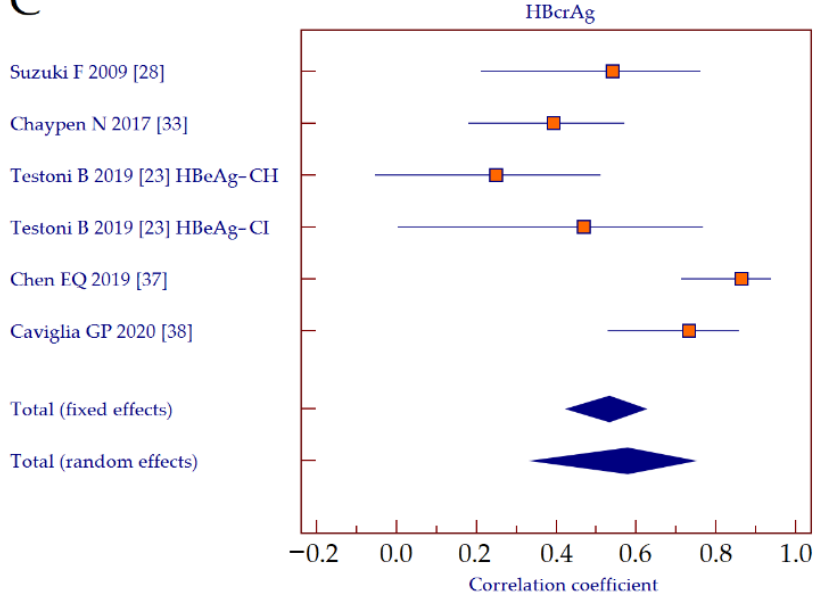

$\mathrm{B}$

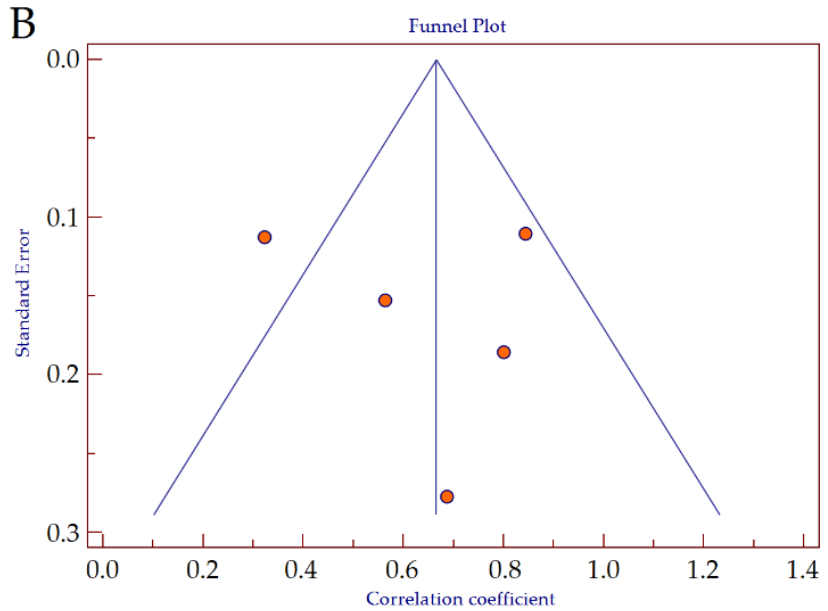

$\mathrm{D}$

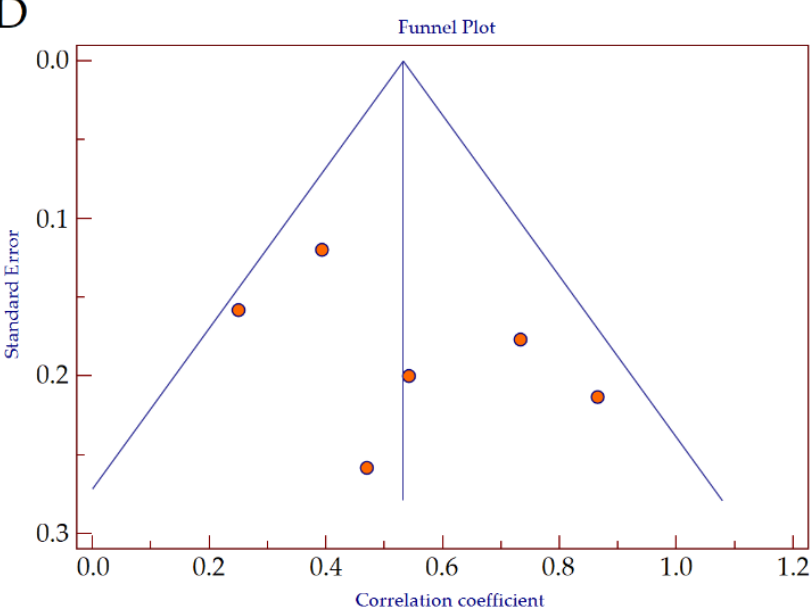

Figure 5. Forest plot (A) and funnel plot (B) of the correlation between serum HBcrAg and intrahepatic HBV cccDNA in HBeAg-positive patients, and forest plot (C) and funnel plot (D) of the correlation between serum HBcrAg and intrahepatic HBV cccDNA in HBeAg-negative patients. Abbreviations: hepatitis B core-related antigen (HBcrAg), hepatitis B e antigen (HBeAg), hepatitis B virus (HBV), covalently-closed-circular DNA (cccDNA).

The correlation coefficients retrieved from studies investigating the between serum $\mathrm{HBcrAg}$ values and intrahepatic $\mathrm{HBV}$ cccDNA in HBeAg-negative patients were analyzed by using forest plot (Figure 5C) $[23,25,30,34,35]$. Since the studies showed heterogeneity (Cochran's $Q, p<0.001 ; I^{2}=77.3 \%$ ), a random effects model was applied. The result showed a moderate positive correlation between HBcrAg and HBV cccDNA $(r=0.578$, $95 \%$ CI 0.344-0.744, $p<0.001)$. The corresponding funnel plot is depicted in Figure 5D. Kendall rank correlation analysis indicated no publication bias $(T=-0.467, p=0.133)$.

By direct comparison of the summary correlation coefficients, we observed no significant differences concerning the performance of HBcrAg between HBeAg-positive and HBeAg-negative patients (z-statistics, $p=0.069$ ).

\section{Discussion}

Different findings of the present meta-analysis are noteworthy. First, the measurement of serum HBcrAg proved to be a reliable non-invasive surrogate of the quantity of intrahepatic HBV cccDNA, despite an overall population of 1271 patients with different demographic, virologic, and clinical characteristics. Second, in a head-to head-comparison, $\mathrm{HBcr} A g$ showed a significantly higher performance compared to serum HBsAg. Finally, serum HBcrAg showed a good correlation to intrahepatic HBV cccDNA reservoir, irrespective of HBeAg-positivity. 
Although no standardized method for HBV cccDNA assessment is currently available, major efforts have been done in the last decades to design sensitive and specific molecular assays for the investigation of the different replicative DNA intermediates of HBV. To improve specificity, it has been shown that treatment of liver DNA extracts with enzymatic digestion prior to PCR amplification is mandatory [40]. However, which could be the more appropriate protocol is still a matter of debate $[6,41,42]$. On this premise, the possibility to accurately infer the amount of HBV cccDNA in the liver by using a standardized, noninvasive, and accurate tool is of considerable clinical relevance. Indeed, novel therapeutic options for the treatment of patients with $\mathrm{CHB}$ are under investigation [43]. Standard antiviral treatment with NAs can inhibit viral replication, but is not curative and must be administered life-long because it is ineffective against the HBV cccDNA [44]. New therapeutic approaches include strategies to prevent HBV cccDNA synthesis, to enhance its degradation, and to silence its transcription [45]. Therefore, it will be crucial to monitor in a non-invasive but accurate manner the modifications to intrahepatic HBV cccDNA quantity induced by therapy $[46,47]$. In this regard, serum HBcrAg qualifies as a suitable tool to be implemented in clinical practice in order to improve the patients' management.

Different biomarkers have been proposed as a surrogate of the intrahepatic HBV cccDNA pool. Here, we performed a direct comparison between $\mathrm{HBcrAg}$ and $\mathrm{HBsAg}$ performance and observed that the former more strongly correlated with HBV cccDNA compared to the latter ( $r=0.665$ vs. $r=0.475$, respectively). As a matter of fact, integrated HBV DNA into the host genome can contribute significantly to the serum expression of HBsAg [48], while HBcAg and HBeAg are translated from the pre-genomic (pg) and pre-core HBV RNAs, that originate solely from the HBV cccDNA [49]. Similarly, the p22cr protein, which contains an uncleaved signal sequence and lacks a C-terminal arginine-rich domain, derives from the pre-core HBV RNA [50]. Furthermore, compared to serum HBsAg [51], recent evidence suggests that $\mathrm{HBcrAg}$ serum values are not affected by $\mathrm{HBV}$ genotype [52]. Taken together, these results further corroborate the reliability of HBcrAg as an indirect biomarker of intrahepatic HBV cccDNA.

Finally, we performed a sub-analysis to assess the performance of HBcrAg according to HBeAg-positivity. The overall correlation observed between serum HBcrAg and intrahepatic HBV cccDNA tended to be higher in the HBeAg-positive compared to HBeAg-negative patients, despite the fact that a statistical significance was not reached. Interestingly, no risk of publication bias was evinced, either by funnel plot evaluation or by Begg and Mazumdar's correlation analysis. Conversely, a high risk of publication bias emerged from the whole analysis of the 14 studies included in the meta-analysis. Likely, among the different characteristics of the 1271 analyzed patients, serum HBeAg-positivity had a significant impact on HBcrAg performance. Consistently, it has been shown that the major variance of $\mathrm{HBcrAg}$ can be attributed to HBeAg in patients with HBeAg-positive chronic infection (i.e., immune-tolerant) and HBeAg-positive chronic hepatitis (i.e., immune-clearance), while HBV DNA is a major determinant of HBcrAg in patients with HBeAg-negative chronic hepatitis [53].

The present meta-analysis has some limitations that deserve to be discussed. As above-mentioned, the overall population included consisted of 1271 patients, mostly of Asiatic ethnicity and predominantly infected with HBV genotypes B and C. Despite three studies assessing HBcrAg performance in Caucasian patients $[23,38,39]$ showing similar results, the data should be interpreted with caution when dealing with patients of ethnicity different from Asian and chronically infected with HBV genotype non-B/C. Another important limitation is that we assessed the value of $\mathrm{HBcrAg}$ as an indirect biomarker of the intrahepatic HBV cccDNA amount, but we did not investigate the value of HBcrAg as a surrogate of $\mathrm{HBV}$ cccDNA transcriptional activity. To date, few studies have investigated such relations, which are not enough to perform a substantial analysis; however, a recent study showed that among serum HBV biomarkers, only HBcrAg was correlated to the pgRNA/cccDNA ratio in HBeAg-negative patients [23]. Further studies are needed to deepen this aspect, also taking into consideration the promising results from studies 
investigating the value of novel potential biomarkers such as circulating HBV RNA [54,55]. Eventually, it would be interesting to evaluate the presence of HBcrAg within exosomes, which are now widely studied for their biomarker and diagnostic potential.

\section{Conclusions}

In conclusion, the measurement of serum HBcrAg represents a reliable non-invasive tool for the indirect assessment of intrahepatic HBV cccDNA. The performance of HBcrAg as a surrogate of $\mathrm{HBV}$ cccDNA quantity was significantly superior to quantitative $\mathrm{HBsAg}$; furthermore, HBcrAg exhibited a strong correlation with the HBV cccDNA pool in both $\mathrm{HBeAg}$-positive and HBeAg-negative patients. To date, the measurement of HBcrAg may represent an appropriate tool to help clinicians in the management of patients chronically infected with HBV.

Author Contributions: Conceptualization, G.P.C.; Methodology, G.P.C. and R.P.; Software, G.P.C., C.R., and D.G.R.; Validation, G.P.C., R.P., and S.F.; Formal analysis, G.P.C.; Investigation, G.P.C., A.A., and R.P.; Resources, S.F.; Data curation, G.P.C., C.R., and D.G.R.; Writing—original draft preparation, G.P.C.; Writing - review and editing, R.P. and S.F.; Visualization, G.P.C.; Supervision, S.F.; Project administration, G.P.C. and S.F.; Funding acquisition, S.F. All authors have read and agreed to the published version of the manuscript.

Funding: This research was funded by Progetti di ricerca di Rilevante Interesse Nazionale (PRIN), grant number 201572SHXJ.

Conflicts of Interest: G.P.C. received research grants from Fujirebio Europe and Fujirebio Diagnostics AB. All other authors declare no conflicts of interest.

\section{References}

1. Seto, W.K.; Lo, Y.R.; Pawlotsky, J.M.; Yuen, M.F. Chronic hepatitis B virus infection. Lancet 2018, 392, 2313-2324. [CrossRef]

2. World Health Organization. Global Hepatitis Report 2017; Global Hepatitis Programme: Geneva, Switzerland, April 2017. Available online: http://www.who.int/hepatitis/publications/global-hepatitis-report2017/en/ (accessed on 21 November 2020).

3. Charre, C.; Levrero, M.; Zoulim, F.; Scholtès, C. Non-invasive biomarkers for chronic hepatitis B virus infection management. Antivir. Res. 2019, 169, 104553. [CrossRef] [PubMed]

4. Caviglia, G.P.; Olivero, A.; Ngatchou, D.; Saracco, G.M.; Smedile, A. Long-term results of chronic hepatitis B antiviral treatment with nucleos(t)ide analogues: A single center experience. Minerva Gastroenterol. Dietol. 2019, 65, 77-78. [CrossRef] [PubMed]

5. Nassal, M. HBV cccDNA: Viral persistence reservoir and key obstacle for a cure of chronic hepatitis B. Gut 2015, 64, 1972-1984. [CrossRef]

6. Caviglia, G.; Abate, M.L.; Tandoi, F.; Ciancio, A.; Amoroso, A.; Salizzoni, M.; Saracco, G.; Rizzetto, M.; Romagnoli, R.; Smedile, A. Quantitation of HBV cccDNA in anti-HBc-positive liver donors by droplet digital PCR: A new tool to detect occult infection. J. Hepatol. 2018, 69, 301-307. [CrossRef]

7. Armandi, A.; Rosso, C.; Ribaldone, D.G.; Caviglia, G. Moving towards core antigen for the management of patients with overt and occult HBV infection. Panminerva Med. 2020. in press. [CrossRef]

8. European Association for the Study of the Liver. EASL 2017 clinical practice guidelines on the management of hepatitis B virus infection. J. Hepatol. 2017, 67, 370-398. [CrossRef]

9. Baudi, I.; Inoue, T.; Tanaka, Y. Novel biomarkers of Hepatitis B and hepatocellular carcinoma: Clinical significance of HBcrAg and M2BPGi. Int. J. Mol. Sci. 2020, 21, 949. [CrossRef]

10. Yang, Y.; Han, Q.; Hou, Z.; Zhang, C.; Tian, Z.; Zhang, J. Exosomes mediate hepatitis B virus (HBV) transmission and NK-cell dysfunction. Cell. Mol. Immunol. 2017, 14, 465-475. [CrossRef]

11. Li, S.; Li, S.; Wu, S.; Chen, L. Exosomes modulate the viral replication and host immune responses in HBV infection. Biomed Res. Int. 2019, 2019, 2103943. [CrossRef]

12. Caviglia, G.P.; Abate, M.L.; Noviello, D.; Olivero, A.; Rosso, C.; Troshina, G.; Ciancio, A.; Rizzetto, M.; Saracco, G.; Smedile, A. hepatitis B core-related antigen kinetics in chronic hepatitis B virus genotype D-infected patients treated with nucleos(t)ide analogues or pegylated-interferon- $\alpha$. Hepatol. Res. 2017, 47, 747-754. [CrossRef] [PubMed]

13. Werle-Lapostolle, B.; Bowden, S.; Locarnini, S.; Wursthorn, K.; Petersen, J.; Lau, G.; Trepo, C.; Marcellin, P.; Goodman, Z.; Delaney, W.E.; et al. Persistence of cccDNA during the natural history of chronic hepatitis B and decline during adefovir dipivoxil therapy. Gastroenterology 2004, 126, 1750-1758. [CrossRef] [PubMed]

14. Thompson, A.J.; Nguyen, T.; Iser, D.; Ayres, A.; Jackson, K.; Littlejohn, M.; Slavin, J.; Bowden, S.; Gane, E.J.; Abbott, W.; et al. Serum hepatitis B surface antigen and hepatitis B e antigen titers: Disease phase influences correlation with viral load and in-trahepatic hepatitis B virus markers. Hepatology 2010, 51, 1933-1944. [CrossRef] [PubMed] 
15. Li, Y.; Cai, Q.; Xie, Q.; Zhang, Y.; Meng, X.; Zhang, Z. Different Mechanisms May Exist for HBsAg synthesis and secretion during various phases of chronic hepatitis B virus infection. Med. Sci. Monit. 2017, 23, 1385-1393. [CrossRef] [PubMed]

16. Caviglia, G.P.; Noviello, D.; Pellicano, R.; Olivero, A. Role of serum hepatitis B core-related antigen in chronic hepatitis B infection. Minerva Biotecnol. 2018, 30, 29-35.

17. Mak, L.Y.; Wong, D.K.-H.; Cheung, K.-S.; Seto, W.-K.; Lai, C.-L.; Yuen, M.-F. Review article: Hepatitis B core-related antigen (HBcrAg): An emerging marker for chronic hepatitis B virus infection. Aliment. Pharmacol. Ther. 2018, 47, 43-54. [CrossRef]

18. Oliveri, F.; Surace, L.; Cavallone, D.; Colombatto, P.; Ricco, G.; Salvati, N.; Coco, B.; Romagnoli, V.; Gattai, R.; Salvati, A.; et al. Long-term outcome of inactive and active, low viraemic HBeAg-negative-hepatitis B virus infection: Benign course towards HBsAg clearance. Liver Int. 2017, 37, 1622-1631. [CrossRef]

19. Riveiro-Barciela, M.; Bes, M.; Rodríguez-Frías, F.; Tabernero, D.; Ruiz, A.; Casillas, R.; Vidal-González, J.; Homs, M.; Nieto, L.; Sauleda, S.; et al. Serum hepatitis B core-related antigen is more accurate than hepatitis B surface antigen to identify inactive carriers, regardless of hepatitis B virus genotype. Clin. Microbiol. Infect. 2017, 23, 860-867. [CrossRef]

20. Höner Zu Siederdissen, C.; Maasoumy, B.; Cornberg, M. New viral biomarkers for Hepatitis B: Are we able to change practice? J. Viral Hepat. 2018, 25, 1226-1235. [CrossRef]

21. Svicher, V.; Salpini, R.; Malagnino, V.; Piermatteo, L.; Alkhatib, M.; Cerva, C.; Sarmati, L. New markers in monitoring the reactivation of hepatitis B virus infection in immunocompromised hosts. Viruses 2019, 11, 783. [CrossRef]

22. Beudeker, B.J.B.; Groothuismink, Z.M.A.; de Man, R.A.; Witjes, C.D.M.; van der Eijk, A.A.; Boonstra, A.; Sonneveld, M.J. Hepatitis B core-related antigen levels predict recurrence-free survival in patients with HBV-associated early-stage hepatocellular carcinoma: Results from a Dutch long-term follow-up study. J. Viral. Hepat. 2021, 28, 205-208. [CrossRef] [PubMed]

23. Testoni, B.; Lebossé, F.; Scholtes, C.; Berby, F.; Miaglia, C.; Subic, M.; Loglio, A.; Facchetti, F.; Lampertico, P.; Levrero, M.; et al. Serum hepatitis B core-related antigen ( $\mathrm{HBcrAg})$ correlates with covalently closed circular DNA transcriptional activity in chronic hepatitis B patients. J. Hepatol. 2019, 70, 615-625. [CrossRef] [PubMed]

24. Moher, D.; Liberati, A.; Tetzlaff, J.; Altman, D.G. Preferred reporting items for systematic reviews and meta-analyses: The PRISMA statement. BMJ 2009, 339, b2535. [CrossRef]

25. Whiting, P.F.; Rutjes, A.W.; Westwood, M.E.; Mallett, S.; Deeks, J.J.; Reitsma, J.B.; Leeflang, M.M.; Sterne, J.A.; Bossuyt, P.M.M. QUADAS-2: A revised tool for the quality assessment of diagnostic accuracy studies. Ann. Intern. Med. 2011, 155, 529-536. [CrossRef] [PubMed]

26. Begg, C.B.; Mazumdar, M. Operating characteristics of a rank correlation test for publication bias. Biometrics 1994, 50, 1088-1101. [CrossRef]

27. Wong, D.K.-H.; Tanaka, Y.; Lai, C.-L.; Mizokami, M.; Fung, J.; Yuen, M.-F. Hepatitis B virus core-related antigens as markers for monitoring chronic hepatitis B infection. J. Clin. Microbiol. 2007, 45, 3942-3947. [CrossRef]

28. Suzuki, F.; Miyakoshi, H.; Kobayashi, M.; Kumada, H. Correlation between serum hepatitis B virus core-related antigen and intrahepatic covalently closed circular DNA in chronic hepatitis B patients. J. Med. Virol. 2009, 81, 27-33. [CrossRef]

29. Hosaka, T.; Suzuki, F.; Kobayashi, M.; Hirakawa, M.; Kawamura, Y.; Yatsuji, H.; Sezaki, H.; Akuta, N.; Suzuki, Y.; Saitoh, S.; et al. $\mathrm{HBcrAg}$ is a predictor of post-treatment recurrence of hepatocellular carcinoma during antiviral therapy. Liver Int. 2010, 30, 1461-1470. [CrossRef]

30. Chuaypen, N.; Posuwan, N.; Payungporn, S.; Tanaka, Y.; Shinkai, N.; Poovorawan, Y.; Tangkijvanich, P. Serum hepatitis B core-related antigen as a treatment predictor of pegylated interferon in patients with HBeAg-positive chronic hepatitis B. Liver Int. 2016, 36, 827-836. [CrossRef]

31. Wong, D.K.-H.; Seto, W.-K.; Cheung, K.-S.; Chong, C.-K.; Huang, F.-Y.; Fung, J.; Lai, C.-L.; Yuen, M.-F. Hepatitis B virus core-related antigen as a surrogate marker for covalently closed circular DNA. Liver Int. 2017, 37, 995-1001. [CrossRef]

32. Chen, E.-Q.; Feng, S.; Wang, M.-L.; Liang, L.-B.; Zhou, L.-Y.; Du, L.-Y.; Yan, L.-B.; Tao, C.-M.; Tang, H. Serum hepatitis B core-related antigen is a satisfactory surrogate marker of intrahepatic covalently closed circular DNA in chronic hepatitis B. Sci. Rep. 2017, 7, 173. [CrossRef] [PubMed]

33. Chuaypen, N.; Posuwan, N.; Chittmittraprap, S.; Hirankarn, N.; Treeprasertsuk, S.; Tanaka, Y.; Shinkai, N.; Poovorawan, Y.; Tangkijvanich, P. Predictive role of serum HBsAg and HBcrAg kinetics in patients with HBeAg-negative chronic hepatitis B receiving pegylated interferon-based therapy. Clin. Microbiol. Infect. 2018, 24, 306.e7-306.e13. [CrossRef] [PubMed]

34. Chen, S.; Jia, J.; Gao, Y.; Li, H.; Fang, M.; Feng, H.; Guan, W.; Ji, J.; Gao, Z.; Gao, C. Clinical evaluation of hepatitis B core-related antigen in chronic hepatitis B and hepatocellular carcinoma patients. Clin. Chim. Acta 2018, 486, 237-244. [CrossRef] [PubMed]

35. Hasegawa, K.; Nishikawa, H.; Enomoto, H.; Iwata, Y.; Sakai, Y.; Ikeda, N.; Takashima, T.; Aizawa, N.; Takata, R.; Yoh, K.; et al. Proposed model for the prediction of intrahepatic covalently closed circular DNA level in patients with chronic hepatitis B. Hepatol. Res. 2019, 49, 271-283. [CrossRef]

36. Wang, L.; Cao, X.; Wang, Z.; Gao, Y.; Deng, J.; Liu, X.; Zhuang, H. Correlation of HBcrAg with intrahepatic hepatitis B virus Total DNA and covalently closed circular DNA in HBeAg-positive chronic hepatitis B patients. J. Clin. Microbiol. 2019, 57, e01303-e01318. [CrossRef]

37. Chen, E.Q.; Wang, M.L.; Tao, Y.C.; Wu, D.B.; Liao, J.; He, M.; Tang, H. Serum HBcrAg is better than HBV RNA and HBsAg in reflecting intrahepatic covalently closed circular DNA. J. Viral. Hepat. 2019, 26, 586-595. [CrossRef] 
38. Caviglia, G.; Olivero, A.; Ciancio, A.; Tandoi, F.; Troshina, G.; Rosso, C.; Abate, M.L.; Younes, R.; Ribaldone, D.G.; Smedile, A.; et al. Analytical and clinical evaluation of a novel assay for anti-HBc IgG measurement in serum of subjects with overt and occult HBV infection. Diagn. Microbiol. Infect. Dis. 2020, 96, 114985. [CrossRef]

39. Dezanet, L.N.C.; Maylin, S.; Gabassi, A.; Rougier, H.; Miailhes, P.; Lascoux-Combe, C.; Chas, J.; Girard, P.M.; Delaugerre, C.; Zoulim, F.; et al. Correlation of serum hepatitis B core-related antigen with hepatitis B virus total intrahepatic DNA and co-valently closed circular-DNA viral load in HIV-hepatitis B coinfection. AIDS 2020, 34, 1943-1949. [CrossRef]

40. Gao, Y.T.; Han, T.; Li, Y.; Yang, B.; Wang, Y.J.; Wang, F.M.; Jing, X.; Du, Z. Enhanced specificity of real-time PCR for measurement of hepatitis B virus cccDNA using restriction endonuclease and plasmid-safe ATP-dependent DNase and selective primers. J. Virol. Methods 2010, 169, 181-187. [CrossRef]

41. Qu, B.; Ni, Y.; Lempp, F.A.; Vondran, F.W.R.; Urban, S. T5 Exonuclease hydrolysis of hepatitis B virus replicative intermediates allows reliable quantification and fast drug efficacy testing of covalently closed circular DNA by PCR. J. Virol. 2018, 92, e01117-18. [CrossRef]

42. Liu, Y.; Zeng, W.; Xi, J.; Liu, H.; Liao, H.; Yu, G.; Chen, X.; Lu, F. Over-gap PCR amplification to identify presence of replicationcompetent HBV DNA from integrated HBV DNA: An updated occult HBV infection definition. J. Hepatol. 2019, 70, 557-559. [CrossRef] [PubMed]

43. Durantel, D.; Zoulim, F. New antiviral targets for innovative treatment concepts for hepatitis B virus and hepatitis delta virus. J. Hepatol. 2016, 64, S117-S131. [CrossRef] [PubMed]

44. Caviglia, G.P.; Abate, M.L.; Pellicano, R.; Smedile, A. Chronic hepatitis B therapy: Available drugs and treatment guidelines. Minerva Gastroenterol. Dietol. 2016, 61, 61-70.

45. Spyrou, E.; Smith, C.I.; Ghany, M.G. Hepatitis B: Current status of therapy and future therapies. Gastroenterol. Clin. N. Am. 2020, 49, 215-238. [CrossRef] [PubMed]

46. Testoni, B.; Levrero, M.; Zoulim, F. Challenges to a cure for HBV infection. Semin. Liver Dis. 2017, 37, 231-242. [CrossRef] [PubMed]

47. Caviglia, G.P.; Pellicano, R.; Saracco, G.; Smedile, A. Hepatitis B core-related antigen: A serum biomarker for intrahepatic covalently-closed-circular DNA. Clin. Lab. 2018, 64, 411-412. [CrossRef] [PubMed]

48. Wooddell, C.I.; Yuen, M.F.; Chan, H.L.; Gish, R.G.; Locarnini, S.A.; Chavez, D.; Given, B.D.; Hamilton, J.; Kanner, S.B.; Lai, C.L.; et al. RNAi-based treatment of chronically infected patients and chimpanzees reveals that integrated hepatitis B virus DNA is a source of HBsAg. Sci. Transl. Med. 2017, 9, eaan0241. [CrossRef]

49. Milich, D.; Liang, T.J. Exploring the biological basis of hepatitis B e antigen in hepatitis B virus infection. Hepatology 2003, 38, 1075-1086. [CrossRef]

50. Kimura, T.; Ohno, N.; Terada, N.; Rokuhara, A.; Matsumoto, A.; Yagi, S.; Tanaka, E.; Kiyosawa, K.; Ohno, S.; Maki, N. Hepatitis B Virus DNA-negative Dane Particles Lack Core Protein but Contain a 22-kDa Precore Protein without C-terminal Arginine-rich Domain. J. Biol. Chem. 2005, 280, 21713-21719. [CrossRef]

51. Brunetto, M.R.; Marcellin, P.; Cherubini, B.; Yurdaydin, C.; Farci, P.; Hadziyannis, S.J.; Rothe, V.; Regep, L.; Bonino, F. Response to peginterferon alfa-2a (40KD) in HBeAg-negative CHB: On-treatment kinetics of HBsAg serum levels vary by HBV genotype. J. Hepatol. 2013, 59, 1153-1159. [CrossRef]

52. Brunetto, M.R.; Carey, I.; Maasoumy, B.; Marcos, C.; van Halewijn, G.; Caviglia, G.P.; Loglio, A.; Cavallone, D.; Scholtes, C.; Smedile, A.; et al. Evaluation of HBV core-related antigen(s) for improving discrimination between HBeAg-negative subjects with chronic infection B versus chronic hepatitis B. Analysis of multicenter data. Hepatology 2018, 68, 1183A-1184A.

53. Zhang, Z.-Q.; Zhang, X.; Lu, W.; Wang, Y.-B.; Weng, Q.-C.; Feng, Y. Distinct patterns of serum hepatitis B core-related antigen during the natural history of chronic hepatitis B. BMC Gastroenterol. 2017, 17, 140. [CrossRef] [PubMed]

54. Mak, L.Y.; Cloherty, G.; Wong, D.K.; Gersch, J.; Seto, W.K.; Fung, J.; Yuen, M.F. HBV RNA profiles in chronic hepatitis B patients under different disease phases and anti-viral therapy. Hepatology 2020. [CrossRef] [PubMed]

55. Carey, I.; Gersch, J.; Wang, B.; Moigboi, C.; Kuhns, M.; Cloherty, G.; Dusheiko, G.; Agarwal, K. Pregenomic HBV RNA and hepatitis B core-related antigen predict outcomes in hepatitis B e antigen-negative chronic hepatitis B patients suppressed on nucleos(t)ide analogue therapy. Hepatology 2020, 72, 42-57. [CrossRef] [PubMed] 